\title{
PLANNED HOSPITAL DISCHARGE: A STRATEGY FOR REDUCING LENGTH OF STAY OF VERY LOW BIRTH WEIGHT (VLBW < 1500G) INFANTS IN NICU
}

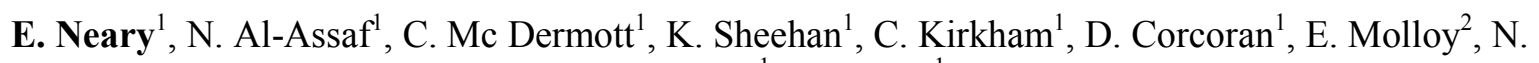 \\ McCallion ${ }^{1}, \mathrm{~T}$. Clarke ${ }^{1}$ \\ ${ }^{I}$ Department of Paediatrics, Rotunda Hospital, ${ }^{2}$ Department of Paediatrics, National Maternity Hospital, \\ Holles Street, Dublin, Ireland
}

Background: Advantages of early discharge of VLBW infants include cost savings, decreased exposure to nosocomial infections, and benefit for families.

Aim: To evaluate the effect of discharge planning on duration of stay of VLBW infants.

Methods: Retrospective review of VLBW infants from 1.1.1996 -31.12.2009.

Results: 850 VLBW infants were discharged home alive, accounting for 49,917 hospital days. Mean LOS was 50.81 days (2009) and was significantly lower than 2004-2007 ( $\mathrm{p}=.015)$, with no increase in readmissions.

$5.6 \%(\mathrm{n}=48)$ had delayed discharge ( $>42 / 40$ CGA) which was less in 2009 than 2007 ( 2 vs 6 infants). Infants discharged $>42 / 40$ CGA had an earlier mean GA (28.5 vs. 29.3 weeks), lower mean BW (870g vs. $1144 \mathrm{~g})$ and mean LOS (117.9 days). Delayed discharge was significantly associated with NEC requiring surgery $(42.9 \%)$, BPD (20.4\%), discharge home on $\mathrm{O}_{2}(22.4 \%)$, or requiring an apnoea monitor. Overall LOS was associated with GA, and sepsis (CONS) $(\mathrm{p}<0.05)$. The total incidence of sepsis decreased from 46 infants per year in 2007 to 25 infants in 2009.

197 infants were transferred to local hospitals. Mean LOS pre transfer was 31.96 days (2009) compared 38.21 days (2007), and significantly reduced compared to 2004-2008 $(\mathrm{p}=.026)$ with no corresponding increased combined LOS in Rotunda and local hospital ( $2007=67.3$ days vs $2009=57.4$ days).

Conclusions: Reduction in mean LOS for VLBW infants with improvement in discharge planning was associated with the appointment of a discharge coordinator. Discharge coordinators are cost effective and should be appointed in all neonatal units. 